AUTORES

William Douglas de Almeida ${ }^{1}$

Katia Rubio ${ }^{1}$

${ }^{1}$ Escola de Educação Física e Esporte da

Universidade de São Paulo
https://doi.org/10.5628/RPCD.18.02.70

\section{O impacto dos migrantes internacionais no esporte olímpico brasileiro}

\section{PALAVRAS CHAVE:}

Imigrantes. Esportes. Atletas.

Brasil. Jogos Olímpicos.

SUBMISSÃ̃o: 8 de Agosto de 2018

ACEITAÇÃo: 30 de Agosto de 2018

\section{RESUMO}

Desde a introdução de modalidades, passando pela fundação de clubes, até mesmo à representação em uma edição olímpica, os imigrantes sempre tiveram um papel importante no desenvolvimento do esporte brasileiro. 0 objetivo é apresentar a trajetória de alguns atletas nascidos em outros países que representaram o Brasil em edições de verão dos Jogos Olímpicos e, por meio delas, destacar a importância destes sujeitos para o esporte nacional. Utilizamos como método as narrativas biográficas, com relatos dos atletas. Como resultados, podemos constatar que mesmo em um ambiente profissional, o esporte tem um papel de destaque na criação de laços entre os indivíduos e o país e serve ainda como um elemento de construção de identificação.
The impact of international migrants

\title{
ABSTRACT
}

From the introduction of modalities, through the founding of clubs, until the representation in an Olympic edition, immigrants have always played an important role in the development of Brazilian sport. The objective here is to present the trajectory of some athletes born in other countries who represented Brazil in summer editions of the Olympic Games and, through them, highlight the importance of these subjects for the national sport. We used biographical narratives, with reports from the athletes who gave interviews to the project "Olympic Memories by Brazilian Olympic Athletes". The results showed that, even in a professional environment, the sport has a prominent role in the creation of bonds between the individuals and the country and still serves as an element of identification construction.

\section{KEYWORDS}

Immigrants. Sports. Athletes.

Brazil. Olympic Games. 
Um dos momentos mais marcantes dos Jogos Olímpicos ocorre antes mesmo das disputas esportivas. Repleta de simbolismos e rituais, a cerimônia de abertura tem como um de seus pontos-chave o desfile das delegações, instante em que os atletas adentram no estádio olímpico, vestindo as cores do país que representam e seguindo a bandeira nacional. É assim desde os Jogos de 1908, realizados em Londres, quando os atletas foram divididos pelos países que representavam. Todavia, nesta época eram ainda permitidas participações individuais de atletas, que podiam indicar em suas fichas de inscrição qual país defenderiam, não estando necessariamente vinculados a um comitê.

Uma mudança significativa marca o Movimento Olímpico em 1914, com uma resolução aprovada durante o Congresso de Paris (Müller, 2000). Com o crescimento dos Jogos Olímpicos e o reconhecimento do papel fundamental no controle das disputas esportivas pelas Federações Internacionais das modalidades, o Comitê Olímpico Internacional (COI) decidiu extinguir a possibilidade de inscrições individuais, sendo necessária aos participantes a vinculação a um Comitê Olímpico Nacional, entidades com jurisdição única, que difere de outras formas de representações políticas e sociais. Atualmente, o COI abarca duzentas e seis nações, e, apesar de organizar os Jogos Olímpicos como um todo, delega às Federações Internacionais a responsabilidade por cada modalidade e o número de nações filiadas a estas federações varia conforme o poder de massificação e divulgação. A utilização do termo nação foi escolhida devido ao COI adotar, na carta olímpica, como termo "Comitês Olímpicos Nacionais". 0 item 30 da carta olímpica esclarece (COI, 2017).

\section{PAÍS E NOME DO COMITÊ OLÍMPICO NACIONAL}

1 - Na carta olímpica, a expressão 'país' refere-se a um estado independente reconhecido pela comunidade internacional

2 - 0 nome de um comitê olímpico nacional reflete uma extensão territorial e as tradições de um país e deve ser aprovado pelo Comitê Executivo do COI" (p.66, tradução dos autores)

Coubertin (citado por Müller, 2000) defendia que o esporte tem uma geografia própria, que difere da geografia política. Assim sendo, lembramos que as definições de nação e país são suscetíveis a discussões e diferentes critérios. Todavia, tendo em vista que a vinculação a um comitê olímpico nacional é um critério necessário para que um atleta participe de uma edição olímpica, temos como objetivo discutir o papel desempenhado por alguns atletas nascidos em outros países e que representaram o Brasil em edições dos Jogos Olímpicos de Verão. Buscamos a compreensão da importância do esporte na identificação destes sujeitos com o país que representam, e também mostrar que eles tiveram um papel importante no desenvolvimento de algumas modalidades.
0 método utilizado para tanto são as narrativas biográficas (Rubio, 2015a, 2015b, 2016) recurso desenvolvido durante a pesquisa "Memórias Olímpicas por Atletas Olímpicos Brasileiros", aprovada pelo Comitê de Ética da Escola de Educação Física da Universidade de São Paulo no processo 0052.0.342.000-09.

De acordo com Rubio (2014), quando os atletas referem-se à sua trajetória esportiva, eles trazem em suas narrativas a lembrança de pessoas e profissionais que influenciaram e determinaram o desejo pelo esporte, pela busca de melhores condições de vida e de treinamento ou a convivência com outros atletas que também competiam naquele momento histórico e cujas carreiras se cruzaram apontando para a necessidade premente de contextualizar essas situações para promover o entendimento de episódios marcantes de suas vidas e de seus resultados. Os atletas foram entrevistados, sendo que o modelo adotado foi a da entrevista aberta, sem o uso de questionários, com o diálogo sendo conduzido a partir do pedido inicial "Conte sua história de vida". A grande maioria das entrevistas foi realizada em português, mas as entrevistas com o jogador de polo aquático Slobodan Soro e com o jogador de hóquei sobre a grama Adam Imer foram realizadas em inglês. 0 encontro com Soro ocorreu após uma partida do Campeonato Brasileiro e, apesar de o jogador ter se comunicado em português com companheiros de equipe (cena presenciada pelos pesquisadores), foi oferecida a ele a oportunidade de realizar o diálogo em inglês, tendo em vista que ele se sentia mais confortável com o idioma. A entrevista com Adam Imer foi realizada via computador e também partiu dos pesquisadores a proposta da conversa em inglês, caso fosse mais confortável para o atleta, tendo em vista que este é o idioma nativo do mesmo. Dois atletas que participaram dos Jogos Olímpicos Rio-2016 ainda não foram entrevistados: Josip Vrlic e Eduard Soghomonyan.

Além disso, foi feita uma revisão de literatura sobre o tema da migração de esportistas e um levantamento de dados divulgados pelo Comitê Olímpico do Brasil sobre a origem dos atletas brasileiros.

PORQUÊ MIGRANTES?

Engh e Agergaard (2015) destacam que a visibilidade dos migrantes no esporte é diferente daquela dada aos atletas autóctones, pois eles sempre são analisados além dos resultados esportivos. Variáveis como o desenvolvimento da modalidade e o aumento da repercussão sobre o esporte acabam por se tornam peças-chave na avaliação sobre o desempenho dos indivíduos que decidiram competir por um país diferente daquele em que nasceram. 0 sucesso ou fracasso dos migrantes muitas vezes é o responsável por atrair ou reprimir a vinda de outros indivíduos do exterior. 
Motta (2012) aponta que as políticas de imigração e nacionalidade são alteradas de tempos em tempos, pois refletem os interesses dos países no controle populacional, inclusive nos direitos das pessoas que por lá circulam. Assim sendo, para analisar a história dos imigrantes que representaram o Brasil em Jogos Olímpicos é preciso ir além dos limites de suas carreiras atléticas.

A denominação "migrantes internacionais" foi adotada tendo em vista que parte dos atletas que nasceram em outros países e representaram o Brasil em Jogos Olímpicos são considerados brasileiros natos, pela figura do jus sanguinis. Segundo a Constituição Brasileira (Senado Federal do Brasil, 1988), em seu Art. 12, item I:

São considerados brasileiros natos: a) os nascidos no Brasil, ainda que de pais estrangeiros, desde que não estejam a serviço de seu país de origem; b) os nascidos no estrangeiro, de pai ou mãe brasileiros, desde que qualquer deles esteja a serviço do País; c) os nascidos no estrangeiro, de pai ou mãe brasileiros, desde que venham a residir no País, e optem a qualquer tempo pela nacionalidade brasileira.

Assim sendo, parte dos atletas que nasceram em outros países, mas que competiram pelo Brasil, é formada por brasileiros natos, que também serão sujeitos deste estudo. Feita tal observação, é relevante apontar que a presença de migrantes internacionais no esporte brasileiro não é uma novidade. 0 quadro abaixo mostra que desde a primeira participação olímpica do Brasil, em 1920, houve a presença de atletas nascidos em outros países na delegação brasileira.

QUADRO1 - Atletas nascidos em outros países que representaram o Brasil em Jogos Olímpicos de Verão.

\begin{tabular}{lccc}
\hline Edição & $\begin{array}{c}\text { Nascidos em outros } \\
\text { países competindo pelo } \\
\text { Brasil }\end{array}$ & Naturalizados & Brasileiros natos \\
\hline 1920 & 1 & 1 & 0 \\
\hline 1932 & 1 & 1 & 0 \\
\hline 1956 & 1 & 1 & 0 \\
\hline 1960 & 3 & 3 & 0 \\
\hline 1964 & 5 & 5 & 0 \\
\hline 1968 & 3 & 3 & 0 \\
\hline 1972 & 3 & 3 & 0 \\
\hline 1976 & 1 & 1 & 0 \\
\hline 1980 & 3 & 2 & 1 \\
\hline 1984 & 1 & 1 & 1 \\
\hline 1988 & 2 & 1 & 1 \\
\hline 1992 & 3 & 2 & 1 \\
\hline 1996 & 5 & 2 & 3 \\
\hline 2000 & 4 & 1 & 2 \\
\hline 2004 & 5 & 3 & 3 \\
\hline
\end{tabular}

\begin{tabular}{lccc}
\hline $\mathbf{2 0 0 8}$ & 3 & 0 & 3 \\
\hline $\mathbf{2 0 1 2}$ & 5 & 2 & 3 \\
\hline $\mathbf{2 0 1 6}$ & 23 & 8 & 15 \\
\hline
\end{tabular}

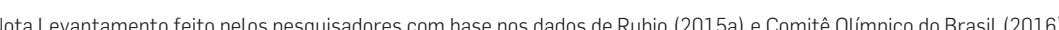

É importante ainda recordar que o papel dos imigrantes no esporte nacional não se resumiu às participações olímpicas. Eles foram fundamentais no desenvolvimento de modalidades pelo país, tal como a introdução do futebol pelos ingleses (Máximo, 1999), do judô pelos japoneses (Nunes, 2011) e a evolução da vela nacional, promovida pelos alemães (Reibel, 2000). Macedo (2008) destaca que várias associações esportivas e clubes brasileiros, que são tradicionais até os dias atuais, foram fundados por imigrantes, que se uniram ao chegarem no Brasil. A formação de sociedades esportivas ajudou aos imigrantes no processo de adaptação, tendo em vista que nestes locais eles encontravam outras pessoas com quem compartilhar experiências e costumes de seus locais de origem, conforme pontua Souza (2012).

Montagna (2017) fala em um componente potencialmente traumático em todo processo de migração. A reunião com outros membros de um mesmo grupo de origem é uma forma de minimizar estes traumas, compartilhando experiências, costumes e recordações. 0 esporte, indubitavelmente, pode ser um destes componentes, funcionando como elo entre 0 país de origem e o de estabelecimento.

A MIGRAÇÃO EM DIFERENTES CONTEXTOS HISTÓRICOS

Chiaki Ishii chegou ao país nos anos 60, após não conseguir a classificação para representar o Japão nos Jogos Olímpicos de Tóquio, em 1964. Segundo Ishii, a intenção ao mudar de país não era seguir atuando como judoca profissional, mas recomeçar uma nova vida no país. "Eu vim pra cá como imigrante, começar de tudo de novo. Aqui tem bastante colônia japonesa. Então, eu cheguei aqui em 64, no ano do Olimpíada de Tóquio. Me formei na Universidade de Waseda e eu vim pra cá. Aí, aqui entrei Universidade, não, na escola Agrícola de Presidente Prudente." (comunicação pessoal, entrevista ao projeto "Memórias Olímpicas por Atletas Olímpicos Brasileiros", em 29 de agosto de 2002).

Ao chegar ao Brasil, porém, Ishii fez contato com outros imigrantes japoneses, que mantinham alguns costumes e tradições do país de origem. Dentre eles, a prática do judô, que foi retomada. Após vitórias em torneios nacionais e com uma cultura esportiva diferente da que era praticada no país (que incluía um volume maior de treinamentos e técnicas específicas), o judoca recebeu o convite para se naturalizar e representar o país em torneios internacionais. Ishii esteve nos Jogos Olímpicos de Munique, em 1972, onde conquistou a medalha de bronze, a primeira da história da modalidade que mais pódios deu ao país até hoje. 
A relação de Ishii com o esporte, todavia, não parou por aí. Após o encerramento da carreira de atleta, ele atuou como técnico, formando novos lutadores e também treinadores que tiveram um papel importante no desenvolvimento do judô brasileiro (Nunes, 2011) Baseando-se em um sistema de classificação desenvolvido por Maguire (2007), é possível considerar Ishii como um migrante pioneiro para o esporte nacional, não apenas pelos resultados esportivos, mas pelas consequências do trabalho desenvolvido por aqui.

Outro pioneiro em um esporte vitorioso no Brasil, mas com uma trajetória muito distinta é o velejador Burkhard Cordes, nascido na Alemanha e medalhista de bronze nos Jogos Olímpicos da Cidade do México, em 1968, ao lado de Reinaldo Conrad na classe Flying Dutchman. Burkhard é filho do ex-jogador de polo aquático Otto Cordes, campeão olímpico de polo aquático pela Alemanha em 1928, e migrou para o Brasil aos seis meses de idade, em 1939, no período que coincide com a eclosão da Segunda Guerra Mundial (comunicação pessoal, entrevista ao projeto "Memórias Olímpicas por Atletas Olímpicos Brasileiros", em 27 de julho de 2016).

Chegando ao país tão jovem, é claro que a iniciação esportiva de Burkhard foi feita já no Brasil. Todavia, a relação entre o esporte e a etnicidade é percebida ao analisarmos a trajetória do velejador. Primeiramente radicado no Rio de Janeiro, Burkhard mudou-se com a família para a cidade de São Paulo no início da adolescência. Devido à origem germânica manteve contato com outros imigrantes, que já viviam na capital paulista naquele período. Parte deles era frequentadora do Yacht Club Santo Amaro (YCSA), clube que foi fundado no início do século XX justamente por alemães que haviam se radicado na Capital Paulista, principalmente na região de Santo Amaro, um dos maiores redutos da imigração alemã no Brasil.

Se não há uma relação direta entre a prática da vela e as origens germânicas de Burkhard, é inegável que a aproximação com o YCSA só ocorreu devido à origem dele. É interessante notar ainda que o clube, fundado em um período onde era grande o fluxo de alemães para São Paulo, manteve como um ponto de encontro entre os novos imigrantes. Procurar comunidades de destino, e pessoas que compartilham os mesmos preceitos culturais é uma forma de facilitar a adaptação ao local de destino, afinal, conforme pontua Golgher (2004):

Amigos e parentes podem ajudar a pagar as despesas da mudança e acolher o recém-migrado. Podem também no destino: oferecer-lhe moradia, comida, amizade e calor humano; arrumar-lhe emprego; informar-lhe sobre as condições do mercado de trabalho existentes no novo local de moradia; diminuir os custos associados à procura de um novo emprego, moradia ou local de residência, etc. Amigos e familiares atuam facilitando, e mesmo possibilitando, a troca de local de domicílio. (p. 35)

No caso de Burkhard, mais que apoio financeiro, a rede de alemães radicados em São Paulo e que frequentavam o YCSA serviu como um ponto de apoio e relacionamento, sendo o esporte um elemento fundamental no fortalecimento dessa relação. Quando um migrante chega a um país distante daquele em que nasceu, encontrar uma comunidade de destino é essencial para que ele se sinta acolhido. Por outro lado, a comunidade formada pelos imigrantes (o clube) foi fundamental para o desenvolvimento da vela brasileira. Além de Burkhard, o YCSA teve um papel fundamental pois foi o local de formação e treinamento de vários velejadores que representaram o Brasil em competições internacionais, como mundiais e Jogos Olímpicos, conforme já apontado por Almeida e Rubio (2017).

UMA QUESTÃO INDIVIDUAL

Nos casos apontados acima, fica clara a relação entre o contexto e a decisão dos atletas em optarem pela nacionalidade brasileira. Em outros, porém, podemos perceber que esta é uma decisão particular, com motivações muito mais íntimas que sociais. É o caso, por exemplo, do tenista Fernando Meligeni, nascido na Argentina e que mudou-se para o Brasil ainda na infância, juntamente com a família. Apesar da troca de país, Meligeni manteve relações com a Argentina: voltou ao país natal para treinar no final da adolescência e teve parte de sua formação esportiva por lá. No momento de participar de competições, porém, Meligeni fez valer o desejo de representar o Brasil, algo que desagradou a própria mãe, que apesar de viver no país não desejava que o filho fizesse a troca de nacionalidade. Apesar dos apelos de Meligeni, ele mesmo teve de fazer toda a documentação de naturalização, sem a ajuda da família, conforme detalha o próprio Meligeni. "Eles gostariam de ter tido um filho argentino, coisa que eles não tiveram" (comunicação pessoal, entrevista ao projeto "Memórias Olímpicas por Atletas Olímpicos Brasileiros", em 24 de fevereiro de 2011).

Seguindo Maguire (2007), Meligeni pode ser considerado um migrante residente, pois, independentemente de fatores esportivos, ele seguiu morando no Brasil e identifica-se com o país. Todavia, é preciso lembrar que feita a escolha em defender o Brasil, o tenista precisou conviver ao longo de grande parte da carreira com questionamentos sobre a opção pela nacionalidade. Para ele, porém, a participação em competições esportivas importantes representando o país acabou sendo um meio de afirmação de identidade.

Eu sou o Fernando Meligeni, muito por causa da Olimpíada, não tenho dúvida disso. Porque o povo, o público, o tenista, o cara que não gosta de tênis, mas, que... que gosta de esporte no Brasil, me conheceu graças a Olimpíada. Isso eu não tenho dúvida nenhuma. Eu poderia ter conquistado três ATP Tour, como eu conquistei, ou cinco ATP Tour, mas, na rua e só falam de duas coisas: falam do Pan-Americano e da Olimpíada. (comunicação pessoal, entrevista ao projeto "Memórias Olímpicas por Atletas Olímpicos Brasileiros", em 24 de fevereiro de 2011).

Outro atleta que conviveu durante grande parte da carreira com questionamentos sobre sua relação com o Brasil é o cavaleiro Rodrigo Pessoa, que nasceu na França, viveu a maior parte da vida na Bélgica, mora atualmente em Mônaco, mas sempre representou o Brasil em competições internacionais. Filho de Nelson Pessoa, um dos principais técnicos de hipismo do mundo, Rodrigo era um dos melhores atletas do mundo em 1992, quando 
participou da primeira edição olímpica. Mas, apesar desta condição, se não estivesse vinculado a um comitê olímpico nacional, não poderia participar de uma edição olímpica. 0 mundo atual permite às pessoas um alto grau de facilidade para circulação e troca de culturas. Porém, estas mesmas pessoas, precisam se instalar dentro de sistemas e, para isso, vincularem-se a lugares, pois, conforme Santos (2000):

0 'mundo' não tem como regular os lugares. Em consequência, a expressão cidadão do mundo torna-se um voto, uma promessa, uma possibilidade distante. Como os atores globais eficazes são, em última análise, anti-homem e anticidadão, a possibilidade de existência de um cidadão do mundo é condicionada pelas realidades nacionais. Na verdade, 0 cidadão só o é (ou não o é) como cidadão de um país. (p. 55)

Cidadão do mundo, Rodrigo opta pela nacionalidade brasileira por questões hereditárias. Mesmo sem ter nascido ou morado no país, constrói uma relação pessoal com a nação de tal maneira que as críticas recebidas pelo seu distanciamento do país o atingem de maneira pessoal. Porta-bandeira do país na cerimônia de abertura dos Jogos Olímpicos de Londres, em 2012, ele teve a sua nacionalidade colocada em xeque pela mídia. Como resposta, ancorou-se não na ancestralidade, mas em sentimentos pessoais. Em depoimento para obra biográfica, ele diz a Deleveau (2014)

Sempre representei o Brasil com muita lealdade e me preocupo com tudo o que se pass no país. Por isso acho que essas críticas não têm fundamento. Eu represento o meu país, já que poderia muito bem ter escolhido outra nacionalidade por razões práticas. (p. 88)

Como se fossem vetores opostos (um nascido no exterior, mas com uma ligação anterior com o país, e o outro sem ligações anteriores, mas radicado no país) as histórias de Meligeni e Pessoa se complementam e mostram que na atualidade a questão do pertencimento a uma nação tornou-se cada vez mais fluída. Ao analisar casos de atletas migrantes, Houlihan (2010) traça um cenário em que as representações nacionais, apesar de continuarem sendo um dos sustentáculos do esporte, são cada vez mais difíceis de serem compreendidas, uma vez que podem ser fundidas, turvas e ambíguas.

2016 - OS MIGRANTES EM EVIDÊNCIA

Em 2016, porém, a questão de atletas que nasceram em outros países na delegação brasileira ficou mais latente, com 23 atletas nesta situação e, apesar de grande parte deles serem considerados brasileiros natos, houve uma grande repercussão midiática sobre 0 tema. Tal fenômeno, porém, não é exclusividade do Brasil. Poulton e Maguire (2012) destacam que às vésperas dos Jogos Olímpicos em Londres a imprensa britânica cunhou a expressão "britânicos de plástico" para referir-se aos atletas naturalizados.
E nem só os países sedes estão sujeitos a tais discussões. A Federação Internacional Atletismo recebeu mais de 250 pedidos de troca de nacionalidade entre os anos de 1998 e 2007 (Campbell, 2010). Ou seja, a troca de nacionalidade é algo frequente no esporte, principalmente no esporte contemporâneo. Poli (2010) mostra que 270 atletas naturalizados participaram dos Jogos Olímpicos de Atenas, em 2004, e um levantamento de Maguire (2014) aponta que dos 48 atletas que participaram dos Jogos de Londres, em 2012, 23 nasceram na China. Entre elas, Gui Lin, que representou o Brasil. À época com 18 anos, Gui Lin vivia no Brasil desde os 12 . 0 processo de migração dela está totalmente ligado ao esporte: mesmo ainda sendo tão jovem, Gui migrou para o Brasil para jogar tênis de mesa, a convite de um técnico. Após participar de seleções regionais na China, ela não via a possibilidade de participar das equipes nacionais em seu país de nascimento e viu na migração uma oportunidade de seguir no esporte. A oportunidade, porém, veio seguida de uma decisão dura de ser tomada, tendo em vista que a legislação chinesa não permite que os cidadãos tenham dupla nacionalidade: ao optar pela cidadania brasileira, Gui precisou abrir mão de seus direitos na China, local onde seus pais vivem até os dias atuais, e que não aceita cidadãos com dupla cidadania (Assembleia Popular Nacional, China, 1980). Assim sendo, temos um exemplo de como uma decisão, aparentemente apenas esportiva, tem reflexos e impactos pessoais na vida de um atleta.

Retomando Maguire (2014), constatamos que o caso de Gui não é isolado, mas algo corriqueiro na modalidade (tênis de mesa). Responsáveis pela elaboração dos regulamentos das disputas, as federações impõe limites para a participação de atletas de um mesmo país nas disputas olímpicas. Assim sendo, por mais que o ranking mundial seja dominado por chinesas, o país só tem o direito de inscrever duas atletas para a disputa individual e uma terceira para a disputa por equipes. Ou seja, a saída da China acaba tornando-se uma possibilidade para que atletas bem ranqueadas no ranking mundial, mas que não estejam nas duas primeiras posições, possam participar dos Jogos Olímpicos, mas por outras nações. A modalidade foi introduzida no programa olímpico em 1988. Desde então, o quadro de medaIhas da modalidade é totalmente dominado pela China, que tem 28 medalhas de ouro, $17 \mathrm{de}$ prata e oito de bronze. A segunda nação com mais pódios é a Coreia do Sul, com três ouros, três pratas e doze bronzes. Ou seja, mesmo com tantos chineses defendendo outros países, o país "exportador" consegue manter-se no topo, segurando os principais talentos por lá.

Maguire (2007) enquadra os atletas que trocam de nacionalidade por questões financeiras na categoria de mercenários. Apesar de reconhecer que o fator econômico tem um peso grande nestas decisões, é importante olhar para este movimento sob outra ótica: a do oportunismo, tendo em vista que talvez, caso permanecesse no país de origem, parte destes atletas não teriam conseguido participar de uma edição olímpica. Este oportunismo deve ser encarado como uma via de mão dupla, uma vez que os países que recebem estes atletas também se aproveitam da oportunidade de ter um competidor qualificado. 
Dentre os quinze brasileiros natos, mas nascidos em outros países que representaram o Brasil nos Jogos Olímpicos do Rio de Janeiro, é possível observar diferentes perfis: parte deles, apesar de ter nascido no exterior, mudou-se logo para o Brasil e construiu toda a trajetória esportiva por aqui (como a velejadora Patrícia Freitas, a nadadora Luísa Borges e as irmãs Tess e Amanda Oliveira, do polo aquático). Outros, porém, sequer haviam morado no Brasil antes de iniciarem a preparação olímpica, como são os casos dos jogadores de rugby Isadora Cerullo e Juliano Fiori (nascidos nos Estados Unidos e Grã-Bretanha, respectivamente).

Filhos de brasileiros que deixaram o país, eles fazem um retorno à terra dos pais e têm a oportunidade de participar de uma edição olímpica. No caso de Juliano, o esporte sempre foi visto como um elo com o Brasil.

Mesmo morando ali na Inglaterra, eu sempre senti uma conexão, através da família, mas também, uma criança com uma identidade confusa, Brasil sempre foi um país com o qual eu me associei. Principalmente em questões de cultura e esporte, meu pai gosta muito de futebol, principalmente, sempre torcia muito pela seleção, apesar de levar muitas críticas no colégio, dos amigos que só falavam que eu torcia pro Brasil porque o Brasi ganhava e a Inglaterra não, mas eu sempre andava com a minha bandeira brasileira no esporte. Então essa ideia de poder representar o Brasil sempre foi um sonho (comunicação pessoal, entrevista ao projeto "Memórias Olímpicas por Atletas Olímpicos Brasileiros", em 7 de outubro de 2016)

No caso de Isadora, a relação com o Brasil era mais distante e a participação olímpica acabou sendo um fator de mudança na relação dela com o país.

Pensando agora num sabia muito bem o que eu tava esperando encontrar no Brasil. Er sim esse sonho olímpico e também essa oportunidade de me aproximar da família, mas também, tipo, a família que eu não conhecia bem [...] Se eu vou ter uma família aqui ou me mudar pra fora, voltar pros Estados Unidos? Talvez, provavelmente, não consigo. Não sei se eu vou só ficar no Brasil, mas eu também de jeito nenhum consigo me ver saindo e nunca mais voltando (comunicação pessoal, entrevista ao projeto "Memórias Olímpicas por Atletas Olímpicos Brasileiros", em 12 de janeiro de 2017)

Fazendo uma nova analogia com os conceitos de Maguire (2007), podemos considerar estes atletas como repatriados. 0 curioso, entretanto, é que eles fazem uma repatriação de um processo no qual a saída do país não foi feita por eles, mas sim por uma geração anterior. Oliveira (2017) aponta que este tipo de movimento é cada vez mais comum e conclui que estes novos migrantes "retornam no sentido figurativo, pois nasceram em outros países e na maioria das vezes nunca estiveram na terra de seus pais, avós e bisavós" (p. 106)

Dentre os atletas que se naturalizaram para representar o Brasil nos Jogos Olímpicos de 2016, é interessante observar que quatro fizeram a troca de nacionalidade após se casarem com brasileiras (Adam Imer, Joaquin López e Chris McPherson, do hóquei sobre a grama, e Ives Alonso, do polo aquático), sendo que os três últimos ainda vivem no Brasil - Adam manteve sua residência na Austrália. 0 matrimônio é utilizado com um fator de facilitação para a concessão de cidadania no Brasil. Todavia, é interessante notar que a relação destes atletas com o país não parou por aí: Ives atua como técnico nas categorias de base do Esporte Clube Pinheiros, em São Paulo, e Chris McPherson trabalha no desenvolvimento do hóquei sobre a grama em Porto Alegre (Almeida \& Rubio, 2018).

Outro atleta que manteve uma relação com o país, porém mais frágil, foi o goleiro da seleção masculina de polo aquático, Slobodan Soro. Natural da Sérvia, ele já havia participado de duas edições olímpicas pelo país natal, mas optou pela troca de nacionalidade após os Jogos Olímpicos de Londres 2012. Maguire (2007) classifica este movimento como sendo o de atletas mercenários, todavia analisando sob uma ótica profissional podemos considerar que Soro agiu de maneira oportunista, fazendo uma transição de nacionalidade dentro das regras dos órgãos reguladores da modalidade e buscando preencher uma lacuna profissional que atendia aos interesses de uma equipe que precisava de mão de obra qualificada - no caso, de um goleiro de alto nível. Além da seleção Soro também passou a atuar pelo Botafogo de Futebol e Regatas e, na temporada 2017, seguiu defendendo o clube carioca na Liga Nacional. Movimentos como o de Soro, de atletas em busca de espaços onde passam jogar, são mais comuns em clubes, mas são percebidos também em equipes nacionais. Além de Soro, o time brasileiro de polo aquático contou com Josip Vrlic, nascido na Croácia, sem relações anteriores com o Brasil, ele optou pela nacionalidade brasileira por uma questão de oportunidade profissional.

\section{O ESPORTE COMO ELEMENTO DE IDENTIFICACC̄̃O DO SUJEITO}

Ainda nos primórdios do movimento olímpico, o Barão Pierre de Coubertin defendia que o esporte deveria ter uma geopolítica própria, sem esquecer, no entanto, que o movimento olímpico necessitava dialogar com outras instâncias de poder, incluindo aí a política. Não há dúvidas que, ao longo do século XX, o Movimento Olímpico tornou-se um exemplo de soft power, uma instância na qual nações aproveitavam para demonstrar poder e capacidade de formar atletas, como um diferencial com outras localidades, apesar do discurso oficial ser que os Jogos Olímpicos são uma competição entre atletas, não entre países.

0 poder dos comitês nacionais, porém, é inquestionável. Todavia, para demonstrar este poder diferentes estratégias foram adotadas ao longo dos tempos. A naturalização de atletas foi uma delas. No caso brasileiro, nos Jogos Rio-2016 houve um aumento no número de atletas nascidos em outros países representando o país, todavia, conforme pudemos notar nos dados acima, a maioria deles já possuía algum vínculo anterior com a nação, por consanguinidade. Apesar de chamar atenção pelo maior volume na última edição, historicamente, o que definiu a presença de indivíduos nascidos em outros países pelo Brasil não foi apenas o desejo por resultados rápidos e retorno imediato, mas a ligação construída por estes indivíduos com o país. 
A generalização ou a leitura precipitada dos números podem levar a crer que a postura brasileira nos Jogos Rio-2016 teria sido apenas de desespero por resultados. Todavia, o resgate histórico e a compreensão das trajetórias destes indivíduos ampliam a visão sobre este fenômeno, percebendo vários migrantes tiveram uma colaboração im portante para o esporte brasileiro e ainda que o esporte é um elemento importante na construção identitária dos atletas.
Almeida, W. D. \& Rubio, K. (2017). Three athletes, two countries cormetion of Almeida, W. D., \& Rubio, K. (2018). Novos brasileiros nos Jogos Olímpicos: A presença de migrantes internacionais na delegação do pais na Rio-2016. Revista Brasileira de Ciência \& Movimento, 26,131-142.

Assembleia Popular Nacional, China (1980). Lei de Nacionalidade da República da China. Disponivel em http://bo.io.gov.mo/bo/i/199g/01/leinac403.asp.

Campbell, R. (2010). Staging globalization for natiohal projects: Global sport markets and elite athletic transnational labour in Qatar. International Review for the Sociology of Sport, 46(1), 45-60.

Comitê Olímpico do Brasil. (2016). Guia para a imprensa: Jogos Olímpicos Rio 2016. Rio de Janeiro, Brasil: Comité Olímpico do Brasit.

Comitê Olímpico Internacional. (2017). Olympic cherter: In force as from 15 September 2017. Lausann Switzerland: International Olympic Committee.

Deleveau, S. (2014). Você será um cavaleiro, meu filho: A saga Pessoa (R. Albert \& B. Toledo, Trad.). Rio de Janeiro, Brasil: Agir.

Engh, M. H., \& Agergaard. N. (2015) Producing mobility through locality and visibility: Developing a bly try tha Internotional Review for the Socilogy of Sport, 50(8). International Review for the Sociology of Sport, $50(8)$ Golgher, A. B. (2004). Fundamentos da migração. Belo Horizonte, Brasil: UFMG/ Cedeplar.

Houlihan, B. (2010). Sport and globalization. In D. Karen \& R. E. Washington (Eds.), The sport and society reader (pp. 292-305). New York, NY: Routledge.

Macedo, R. L. (2008, outubro/ novembro). 0 esporte no estado novo: Vigilância, formação e controle em época e guerra. Curitiba. Comunicação oral apresentada no - Encontro da Asociación Latinoamericana de Estudios Socioculturales del Deporte (ALESDE). Esporte n mérica Latina: Atualidade e perspectivas, Universid de Federal do Paraná, Curitiba, Paraná, Brasit. Maguire, J. (2007). 'Política' o 'ética'. Deporte, globamigracion-y-politcas-nacionales.htm
Maguire, J. (2014). Assessing the sociology of sport: nal Review for the Sociology of Sport. 50(4-5), 519-523. Máximo, J. (1999). Memória do futebol brasileiro (Vol. 13). São Paulo, Brasil. Estudos Avançados.

Montagna, P. (2017). Alma migrante. Revista USP 114, 109-118.

Motta, D. S. (2012). Migrações internacionais: A afirmação do indivíduo enquanto sujeito de direito internacional para a concretização do direito humano e fundamental de migrar (Monografia de bacharelado não publicada). Centro Universitário de Brasília, Brasil. Müller, N. (Ed.). (2000). Pierre de Coubertin 1863 1937: Olimpism selected writings. Lausanne, Switzerland: International Olympic Committee.

Nunes, A.V. (2011). A influência da imigração japonesa no desenvolvimento do judô brasileiro: uma genealogia dos atletas brasileiros medalhistas em Jogos Olimpicos e campeonc publicada). Escola de Educação Física e Esporte, Universidade de São Paulo, Brasil.

Oliveira, A. C. (2017). Uma questão de identidade! Migrações e pertencimento na dinâmica do mundo globalizado. Revista da USP, 114, 91-108.

Poli, R. (2010). The denationalization of sport. De-ethnicization of the nation and identity de-territoralization. In D. Karen \& R. E. Washington (Eds), The sport and society reader (pp. 322-331). New York, NY: Routledge

Poulton, E., \& Maguire, J. (2012). 'Plastic or fantastic Brits? Identity politics and English media representations of 'Team GB' during London 2012. JOMEC Journal, 1(2), 1-30.

Reibel, E. (2000). Soprando as velas: YCSA 70 anos 1930-2000. São Paulo: Yacht Club Santo Amaro.

Rubio, K. (2014). Memórias e narrativas biográficas de atletas olímpicos brasileiros. In K. Rubio (Org.). Preservação da memória: A responsabilidade social dos Jogos Olímpicos (pp. 105-122). São Paulo, Brasil: Képos. Rubio, K. (2015a). Atletas olímpicos brasileiros. São Paulo, Brasil: Sesi-SP Editora.

Rubio, K. (2015b). Biographical narratives of Olympic athletes: An access road to identity and Brazilia sports imagery. American International Journal of Social Science, 4, 85-90. 
Senado Federal do Brasil. (1988). Constituição da República Federativa do Brasil. Brasília, Brasil: Senado Federal, Secretaria de Editoração e Publicaçōes. Disponivel em https://www2.senado.leg.br/bdsf/bitstream/handle/id/508200/CF88_EC85.pdf?sequence $=1$ Souza, J. U. (2012). 0 clube e suas múltiplas faces: Notas sobre futebol, imigração e pertencimento. Revista de História Regional, 17(2), 505-533.

José Afonso

Isabel Mesquita

Centro de Investigação, Formação, Inovação e (CIFI'D), Faculdade de Desporto, Universidade do Porto, Portugal

https://doi.org/10.5628/RPCD.18.02.85
How do coaches from

individual sports engage

the interplay between long-

\section{and short-term planning?}

A study with five coaches

from four different sports.

KEYWORDS:

Planning. Training theory.

Constraints. Unpredictability.

Thematic analysis.

SUBMISSÃO: 7 de Fevereiro de 2018

ACEITACÃO: 15 de Julho de 2018

\section{ABSTRACT}

A wide body of research has focused on planning in different temporal structures, from the long-range year cycle to the short-term training unit. What is lacking in research is the scrutiny of how coaches apply these concepts in training settings. Therefore, our purpose was to examine how coaches from individual sports handled the dynamics between short- and long-term planning. Five high-level coaches (i.e., engaging in international competitions in representation of clubs and/or national teams) from four different sports (canoeing, gymnastics, middle-distance racing, and swimming) were interviewed using a semi-structured script. Data was analyzed using thematic analysis. The results provided four major insights: (a) regarding temporal order, long-term planning was vague, acting as a guideline; (b) short-term planning, especially the training week and training unit, was detailed and partially independent of long-term planning, albeit varying from coach to coach: (c) long-term planning was focused mostly on the 'physical' aspects of performance, followed by technique, while tactical aspects represented a side-note and psychological aspects were overlooked; and (d) unforeseen events, unpredictable learning rates and several unknowns are pervasive in the training process. In conclusion, a gap seems to exist between theoretical models of planning and the constraints posed by training settings. Nonetheless, our sample is limited and generalization is not advised. 